\title{
Why Study the Maternal Now?
}

\section{Tracey Jensen}

According to one popular parable, parenting has seven times more impact on a child's future than education. Seven times - can you imagine? Sadly, I cannot remember how this charming factoid entered my consciousness, nor could I imagine how such findings might have been confidently measured. In some ways, the easy commonsense repetition of these claims, and their discursive effects, are far more interesting than any 'evidence' anyway. For instance: 'good parenting in the home is more important than anything else to a child's future', ${ }^{1}$ or 'what happens at home is far more important than the best nursery or the best teacher'. And again: 'every time someone asked [former US president Bill] Clinton what his campaign was about, he used the expression: "It's the economy, stupid." Well, I think: "It's the parenting, stupid.", 3

These official utterances around parenting endeavour to formalise a triumph of feminism by interpellating both mothers and fathers, 'parents'. They also promise that it is through childrearing practices - producing something called 'good parenting' and annihilating something called 'poor parenting' - that a meritocratic playing field can be guaranteed for all children. No child left behind, every child mattering; these things are not brought about by a redistribution of wealth or resources or a thoughtful examination of education, housing or economic policies which structurally disadvantage the poor. They are, according to the promise of 'parenting', a case of learning the right skills. These utterances sanction a fantasy of the genderless 'parent', obscuring the burden of care that remains overwhelmingly with mothers. And curiously - frustratingly, when a magnitude of evidence points to the stagnation of social mobility - this genderless 'good parenting' is offered to us rhetorically as a guarantee of mobility itself. In this wilful collapse of the unequal distributions of wealth, resources and symbolic capital, the obscuring of the classed privileges that permit certain practices and dispositions to become silently marked as 'normal', 'desirable' and 'attainable', blame for the child is laid squarely, and only, at the feet of the 'parent', now marked as 'poor'. The empty guarantee of mobility through 'good parenting' has a flipside; it functions as an alibi, absolving all but the careless or negligent (or just plain stupid) parent when the promised mobility continues to not happen. The discursive effects of the notion of "poor 
parenting' are multiple: a slippage between two meanings of the word 'poor' itself, and a cloaking of the gender of the very-much-gendered parent who is considered to be parenting poorly. The familiar face of the working-class mother emerges as the usual suspect.

This is absolutely the time to take Maternal Studies seriously, to give serious critical attention to the contemporary fantasy that parenting creates a level, genderless playing field, unmarked by landscapes of disadvantage. The notion that once we become parents social divisions fall apart, uselessly represents a particular refusal to engage with these landscapes. To cite Polly Williams, 'And then, of course, there are those like me, stripped of signatures of class by the raw shock of motherhood' (Williams 2006, p.42). Or Naomi Stadlen: 'Motherhood can be a great leveller. Faced with a crying newborn, the usual social differences vanish. Wealth, power and success, and usually race and ideology, suddenly seem unimportant. What counts is the sharing of motherly experience' (Stadlen 2004, p.5). By intervening in a site we can call 'the maternal', we can challenge the idea that the 'realness' of maternity is experienced in similar ways, across an even landscape. Or that the maternal strips us of our differences and signatures. Motherhood, far from being the 'great leveller' envisaged by these authors, is not simply a site for new social divisions, but has become another site for the performance of social distinction itself. Maternal Studies is, amongst other potentials, a way of disrupting the romance of mothers bonding and differences vanishing. At this cultural moment, when 'parenting' is held to be the most important social provocation of a child's future, the enormous burden placed upon parents - or to use a more accurate term, upon mothers - must be interrogated within a transdisciplinarity space we can call Maternal Studies.

Of course, I am not suggesting that mothers shrug off responsibility for their children, any more than feminists are 'anti-family'. But the profound symbolic accountability which is being constructed around 'parenting' and that is coming to function as an alibi for the failures of welfare, meritocracy and social justice, must be genuinely challenged. The ability to speak meaningfully about these failings is in real danger of being lost in this moment of individualisation, of progressive politics eroding under a thoughtless mantra of 'personal responsibility' which presumes to flatten out landscapes of inequality. In the case of mothering, this individualisation unfolds even more readily, the chronicles of mothering being, as they are, a generational rehearsal of taking the blame, being at fault, failing one's 
children, being selfish, not doing 'good enough mothering', feeling ambivalent and sacrificing too little. The challenge is more urgent at the site of the maternal, a site where it is particularly difficult not to absorb the realness of accountability, to hold multiple tensions in place. I as reminded of this when my five-year old deftly out-reasoned me: 'That's your other name. Your real name is mummy.'

\section{References}

Gillies, V., 2005. Marginalised Mothers: exploring working-class experiences of parenting. Abingdon: Routledge.

Stadlen, N., 2004. What Mothers Do: Especially When it Looks like Nothing. London: Piatkus Books. Williams, P., 2006. The Rise and Fall of the Yummy Mummy. London: Time Warner.

\footnotetext{
${ }^{1}$ Margaret Hodge, former Children's minister, Parent-child 2004 conference (cited in Gillies 2005, p.839)

${ }^{2}$ Prime Minister Tony Blair, speech to Daycare Trust, 11.11.04.

${ }^{3}$ Louise Casey, head of the Respect unit, interview with Patrick Wintour in The Guardian 26.07.06.
} 